\title{
DESMILITARIZAÇÃO DAS POLÍCIAS, POLÍTICA CRIMINAL E DIREITOS HUMANOS NO ESTADO DEMOCRÁTICO DE DIREITO
}

\author{
DEMILITARIZATION OF THE POLICE, CRIMINAL POLICY AND HUMAN \\ RIGHTS IN THE DEMOCRATIC RULE OF LAW
}

\author{
${ }^{1}$ Igor Frederico Fontes de Lima \\ ${ }^{2}$ Ilzver de Matos Oliveira
}

\section{RESUMO}

O presente artigo propõe uma reflexão acerca da incompatibilidade entre a militarização das polícias e o Estado Democrático de Direito. Enxergando os mecanismos violentos como rotineiros, relaciona-se o modelo de segurança pública com os ensinamentos de Agamben acerca do estado de exceção como regra. A cultura do medo é apontada como legitimadora do anseio social por mais aparato militarizado. Relacionando Bauman, Zaffaroni e Foucault, o trabalho aponta que a política criminal tem como fundamento a aniquilação do diferente e que o sistema penal é extremamente seletivo, utilizando as PM's para a verticalização e padronização de perfis aceitáveis.

Palavras-chave: Desmilitarização, Polícia, Política, Estado democrático de direito

\begin{abstract}
This article proposes a reflection on the incompatibility between the militarization of the police and the democratic rule of law. Seeing the violent mechanisms such as routine, relates to public safety model with Agamben's teachings on the state of exception as the rule. The culture of fear is seen as legitimizing the social longing for more militarized apparatus. Reconnecting Bauman, Zaffaroni and Foucault, the work points out that criminal policy is based on the annihilation of the other and that the penal system is extremely selective, using the PM's for vertical integration and standardization of acceptable profiles.
\end{abstract}

Keywords: Demilitarization, Police, Policy, Democratic state

\footnotetext{
${ }^{1}$ Mestrando em Direitos Humanos na Universidade Tiradentes - UNIT, Aracaju - SE (Brasil). E-mail: igorfflima@gmail.com

${ }^{2}$ Doutor em Direito pela Pontifícia Universidade Católica do Rio de Janeiro - PUC, Rio de Janeiro - RJ. Professor da Universidade Tiradentes, UNIT Aracaju - SE (Brasil). E-mail: ilzvermatos@gmail.com
} 


\section{INTRODUÇÃO}

O debate acerca da violência policial contra a população brasileira encontra-se em um novo patamar. Em que pese a violência de Estado ${ }^{1}$, através de seu braço policial, não ser novidade, desde as grandes manifestações de junho de 2013 os abusos ficaram nítidos até para os mais conservadores. A publicização de arbitrariedades, execuções, sequestros, fraude de provas e etc, pelos meios de comunicação independentes e, principalmente, pelas redes sociais abriram uma nova oportunidade para a discussão acerca do nosso modelo de segurança pública.

Têm-se problemas e questões que nortearão a pesquisa: quais os princípios básicos do militarismo? Quais as consequências da implementação de uma segurança pública militarizada para o processo de construção social? Há incompatibilidades entre a ideia de Estado Democrático de Direito e uma segurança pública militarizada? A verticalização de valores e condutas como produção ideológica de um ser humano aceitável representa a militarização da vida?

A mídia no Brasil não é democratizada e os meios de comunicação em massa pertencem a um pequeno número famílias e de grandes grupos empresariais. No entanto mesmo com o grande empenho desses meios ligados a empresários e aos interesses do poder, houve um avanço de qualidade significativo na discussão apontando para a ruptura com o atual modelo de segurança.

A violência oriunda da repressão estatal, materializada principalmente nas condutas empreendidas pelas polícias militares, tem, num ritmo cada vez mais acelerado, conquistado bastante atenção do meio social, mesmo num contexto formalmente democrático. A relação conflituosa entre as Polícias Militares e a sociedade ficou mais flagrante desde as "jornadas de junho", quando grandes manifestações se espalharam pelo Brasil, sendo brutalmente reprimidas pela segurança pública militarizada. Em diversas oportunidades essa inaceitável situação de constantes violações fora denunciada por iniciativa de entidades nacionais e internacionais que atuam na defesa dos direitos humanos, a exemplo do emblemático caso do pedreiro Amarildo, assassinado por policiais no Rio de Janeiro no ano de 2014. Em que pese o empenho de tais organismos a tendência brasileira em lidar com a segurança pública vai mais no sentido

\footnotetext{
${ }^{1}$ Nesse artigo o termo violência de Estado será utilizado para designar todo ato "[...] tolerado ou incentivado pelo Estado com a finalidade de criar, justificar, explicar ou reproduzir hierarquias de diferença e relações de desigualdades. São atos de violência estatal mesmo que o Estado não apareça diretamente como seu agente primário.” (NAGENGAST, 1994, p. 114).
} 
da afirmação do militarismo enquanto detentor da formação e implementação da linha de atuação do país na segurança pública.

Não obstante a crescente visibilidade do tema nos últimos anos, a atuação violenta do poder constituído não é novidade alguma para as camadas mais pobres, pois desde suas origens a polícia brasileira leva, mediante força, às periferias das cidades, compostas pelas camadas populares, o controle do Estado.

Para isso foi criado o Corpo Policial Permanente, na época da transição do modelo de produção rural e escravocrata para o industrial assalariado. A missão era tornar "civis" os escravos recém-libertos, famintos e desempregados. Partindo da ideia de "população incômoda" é trabalhada a concepção de segurança pública com base na doutrina militar que pressupõe existência de um inimigo a ser combatido.

Num Estado Democrático de Direito, a segurança pública deve ter como objetivo tutelar direitos e cidadãos. Por ser, em sua forma, Democrático, o Estado deve conviver com experiências radicais de democracia. Entretanto ao verificar historicamente o papel exercido pelas Polícias Militares dos estados-membros do Brasil podemos constatar que faz parte de sua estrutura o combate ao cidadão que aja em desacordo com a lei ou com os interesses de quem detém o controle político. Isso não é acidental ${ }^{2}$.

O militarismo tem como alicerces ideológicos três pilares rígidos, quais sejam: a hierarquia, a disciplina e a existência de um inimigo a ser combatido. Embora essa forma de organização faça algum sentido para a defesa da soberania de um país, através de suas forças armadas, é inconcebível para a segurança pública interna num Estado Democrático de Direito, uma vez que é totalmente incompatível com a defesa de direitos humanos.

Habitualmente o nascimento do discurso em torno dos direitos humanos é atribuído às revoluções impulsionadas pela burguesia no século XVIII. Essa associação não é feita sem uma medida de razão uma vez que a Revolução Francesa deixou como legado valores como igualdade, liberdade e fraternidade que se transformaram em princípios básicos para a construção discursiva.

Tomando como marco da fundação dos direitos humanos na modernidade a Declaração dos Direitos do Homem e do Cidadão (1789), é importante diligenciar acerca dos direitos por ela enunciados, bem como dos enunciados posteriormente. Tal investigação tem

\footnotetext{
2 Amparo-Alves (2010, p. 570) ressalta as contribuições de Giorgio Agamben (2005) para a desmistificação dos mecanismos de poder nas democracias modernas, em especial a denúncia de que o estado de exceção, marcado pela suspensão da ordem jurídica em nome de um estado de necessidade, tem se tornado uma regra, perdendo sua essencial extra-legal para aparecer como uma forma legal, de modo que o estado de exceção tem se tornado a figura paradigmática da arte de governar. Tudo isso expõe os limites do Estado democrático de direito e as fragilidades dos princípios universalistas de direitos humanos, já apontada por diversos autores como Joaquín Herrera Flores, David Sanchez Rúbio e Boaventura de Souza Santos.
} 
como objetivos verificar o grau de interferência real na vida dos seres humanos dessas previsões de direitos e, principalmente, observar, a partir de uma perspectiva da teoria crítica de direitos humanos, se a atual política de segurança pública se faz suficiente para emancipar e libertar as pessoas das amarras que as formas mais modernas de organização societária impõem.

Para o desenvolvimento dessa pesquisa é fundamental perceber que, embora os militares protagonizem violações a direitos e sejam os grandes atores bélicos, os interesses e ideologias dominantes desempenham um grande papel na constituição e no exercício dos aparatos repressores. Uma vez que o militarismo serve a interesses e ideais é necessário que o direito se debruce em seu estudo, pois os impactos de uma linha política segregadora inviabilizam a concretização de direitos fundamentais. Assim sendo militarizar as polícias é também militarizar a política, haja vista que, embora os militares sejam treinados para combater e exterminar inimigos, é a política que constrói o inimigo.

A segurança pública é um setor estratégico do atual estágio de organização societária que a humanidade se encontra. A sua estrutura deve estar a serviço da proteção de bens jurídicos e dos cidadãos. Para tanto é condição sine qua non o estudo das ideologias que movem as políticas de segurança pública. O presente estudo, elaborado no bojo de projeto de pesquisa apoiado pela Fundação de Apoio à Pesquisa e Inovação do Estado de Sergipe - FAPITEC/SE, propõe-se a uma análise crítica da militarização das polícias enxergando-a num contexto de limitação das concepções tradicionais de direitos humanos.

\section{PROCEDIMENTOS METODOLÓGICOS}

No presente estudo, no que diz respeito à metodologia de abordagem, será empregado o método dialético, uma vez que os fenômenos sociais e jurídicos que circundam o tema serão analisados como processos que passam por transformações diversas existindo tão somente como um todo, jamais de maneira isolada. Além disso, o estudo da militarização da segurança pública a partir da Teoria Crítica de Direitos Humanos fomenta uma necessária tensão entre correntes de pensamento - teoria crítica x teorias tradicionais - que possibilitam uma transformação do pensamento jurídico hegemônico, através de mudanças quantitativas e qualitativas nos âmbitos teórico e prático. 
No que tange à metodologia de procedimento, será aplicado o método histórico, uma vez que se faz imprescindível a construção de uma trajetória histórica da militarização das polícias no Brasil, bem como estudar historicamente a cultura punitivista e vingativa possibilita a verificação dos contextos que influenciaram a construção do pensamento hoje hegemônico que estabelecem a dor e o castigo físicos como resposta obrigatória ao ilícito penal.

No tocante à técnica de pesquisa, será adotada a documentação indireta, tendo como foco a pesquisa documental e bibliográfica. Serão utilizados documentos e estatísticas fornecidas por entidades estatais e não-estatais, nacionais e internacionais que atuem em defesa de direitos humanos e, principalmente, livros nacionais e estrangeiros que abordem a temática dos direitos humanos, sociologia, direito constitucional, direito administrativo, direito penal, criminologia e filosofia jurídica, artigos científicos, a própria Constituição Federal e normas infraconstitucionais. (MARCONI; LAKATOS, 2003, p. 100-106)

\section{INCOMPATIBILIDADES ENTRE A MILITARIZAÇÃO DAS POLÍCIAS E O RESPEITO A DIREITOS HUMANOS}

A segurança pública é um setor estratégico para a implementação de uma política de Estado que tenha como base uma pauta de direitos humanos que pretenda concretizar as conquistas históricas e efetivar a dignidade da pessoa humana. No Brasil há uma tendência de reduzir o significado de segurança à intervenção policial, o que causa uma confusão de conceitos que culmina em diversas formas de violência que são cotidianamente sentidas pela população. Agrava esse cenário o fato de as polícias que fazem o trabalho ostensivo e mais visível serem militarizadas e, portanto, viverem uma guerra constante contra os cidadãos.

Machado (2005) constata que cresce, num cenário de intensificação de desigualdades sociais, a sensação de insegurança da sociedade civil que tem como consequência o clamor público pela intensificação daquilo que é difundido como segurança. Se em algumas áreas o meio social entende que o aparelho estatal não deve intervir, no tocante a segurança ocorre o inverso, há uma expansão das demandas por segurança pública, que se transforma num dos principais instrumentos de organização da vida social (MACHADO, 2005, p. 85).

Uma parte significativa da sociedade tem seu sono prejudicado pela fome, uma outra parte, também significativa, tem seu sono igualmente prejudicado por temer a outra parcela, a que tem fome. As pessoas que tem fome não têm acesso aos seus direitos mínimos, vivem 
sem dignidade. As outras têm medo. É com base nesse medo - exagerado - que se dá o recrudescimento das PMs. Os que vivem bem têm medo dos que vivem mal e, por isso, se afastam deles, o que gera uma segregação social que só contribui para a marginalização de um setor que sempre teve os seus direitos negados e que fica cada vez mais vulnerável. Ressaltase que essa é uma opção política do Estado. Entre gerar oportunidades e exterminar os “incômodos”, politicamente o Estado opta pelo extermínio.

A “cultura do medo" também é apontada por Pastana (2009), como influenciadora direta de políticas de controle da criminalidade embasadas no recrudescimento das polícias. Além de causar mudanças nefastas no convívio social - a segregação social é a mais notávelo medo tem como consequência anseios de endurecimento e respostas mais violentas por parte do Estado como antídoto contra o cometimento de ilícitos penais. Essa "cultura" é, destarte, uma das grandes táticas políticas para gerar no meio social o anseio legitimador para a militarização e o autoritarismo policiais (PASTANA, 2009, p.55).

Apontar e polícia como remédio único para o medo demonstra uma confusão importante para o entendimento do que vem a ser segurança pública. Como já dito, o discurso dominante atrela segurança à polícia - em regra militar. Essa ideia é, ao mesmo tempo, canalha e esquizofrênica, pois é nas áreas mais pobres das cidades onde há mais policiamento, porém é nessas mesmas áreas onde há mais insegurança. Entretanto essa ideia é exaustivamente difundida pelos poderes constituídos com auxílio da grande mídia, demonstrando a força da política autoritária remanescente, mas também a opção que o sistema capitalista faz em tratar a população mais pobre como problema de polícia. A polícia não se faz presente nas favelas para garantir a segurança das pessoas que nela moram, mas para impor a essas pessoas o comportamento que não agrida os interesses da parcela dominante.

No Brasil não é novidade a força do autoritarismo e da militarização, aliás, nem na América latina. Piovesan (2011) analisa que, assim como em outros países latino-americanos que têm em sua história as marcas de regimes ditatoriais, no Brasil não há uma democracia consolidada e, para consolidá-la, faz-se necessária a ruptura com qualquer legado de cultura autoritária deixado pelas ditaduras militares, enfrentando, portanto, as mais flagrantes violações a direitos humanos (PIOVESAN, 2011, p.124 - 125).

A influência desse legado autoritário no Brasil pode ser sentida de diversas formas, inclusive pela inserção que setores sociais ligados à ditadura militar têm nos meios de comunicação em massa. Algumas emissoras de rádio e TV, bem como mídias escritas, trazem em sua programação um espaço reservado a programas e discursos policialescos. Fruto de 
opções conciliatórias o novo estágio da democracia brasileira, pós-golpe de 1964, necessita de rupturas radicais com qualquer tipo de resquício dessa cultura tirânica que insiste em povoar os aparelhos ideológicos e as instituições do país.

Entretanto, mesmo com o fim da ditadura o militarismo continuou com muita força dentro do Estado Brasileiro. Em que pese o início do processo de redemocratização, a ideologia militar segue como protagonista e responsável pela formulação e aplicação das políticas de segurança pública interna, através das PM`s. A opção política do país foi pela redemocratização progressiva e pactuada, que tem como símbolo a Lei de Anistia que consagra a impunidade dos crimes contra a humanidade cometidos por agentes do estado no período compreendido entre 02 de setembro de 1961 e 15 de agosto de 1979.

Feita essa breve análise, fica perceptível que o debate em torno da militarização das polícias tem como plano de fundo, questões ideológicas. É próprio das instituições militares o embasamento filosófico, moral, doutrinário, etc. Todos os conflitos protagonizados pelas forças militares são previamente analisados e seus inimigos são previamente construídos e, portanto, conhecidos.

Para que toda essa abordagem acerca da ideologia que move as ações policiais e a atual política de segurança fique mais clara é importante construir um histórico da militarização das polícias no Brasil. Partindo da ideia de aparato policial como instrumento para a condução da “população incômoda" para controle das classes dominantes e do Estado, é importante verificar que no século XIX o Império necessitou criar um organismo repressor para adequar os conflitos aos seus interesses. A criação do Corpo Policial Permanente, nesse cenário, se apresentou como medida para a "civilização" de negros recém-libertos ${ }^{3}$ e insatisfeitos com a forma de organização social que, mesmo após o fim da escravidão, negava às classes menos influentes o direito à dignidade. $\mathrm{O}$ modelo brasileiro de segurança involuiu e já com a proclamação da República a polícia recebeu a designação Militar. Em 1915, um ano após a eclosão da Primeira Guerra Mundial as Polícias Militares, que já se encontravam subordinadas aos estados e com nomes diferentes em cada localidade, foram formalmente transformadas em forças reservas do Exército. A vergonhosa ditadura militar fez mais

\footnotetext{
3 Amparo-Alves (2010, p. 567), existe uma obsessão pelo corpo negro que historicamente nutre sentimentos aparentemente antagônicos entre si: desejos e medos, ambos irracionais. Para o autor, existe uma paranoia que povoa o imaginário das elites em relação ao corpo negro e foi essa paranoia que alicerçou o terror racial no Brasil Colônia, as teorias eugenistas do século XIX, a configuração territorial das cidades brasileiras, mas, especialmente, o surgimento do aparato policial e as narrativas contemporâneas da violência urbana (ainda profundamente racializadas). Assim, Amparo-Alves (2010) esclarece como que a favela aparece nesse imaginário da elite racista como "o lugar dos maus" e "o espaço reservado aos criminosos" e como que a racialização do medo na imprensa fundamenta-se nos estereótipos da "família negra como ente patológico", do "homem negro como criminoso" e da "mulher negra como promíscua e degradante".
} 
modificações, dentre as quais se destaca a criação da Inspetoria Geral das Polícias Militares (IGPM) que era diretamente subordinada ao Exército. No pós-ditadura não tivemos avanços, inclusive o IGPM foi mantido pela Constituição de 1988 e fortalecido no governo de Fernando Henrique Cardoso (LIMA, 2015, p. 170-171).

Faz-se extremamente necessário entender as origens do modelo de segurança pública que temos, bem como contextualizar as fases de organização militar, para que possamos perceber que em todos esses momentos existe um elemento que se repete, existe um elemento comum: inexoravelmente a polícia militar foi utilizada para executar a política segregadora e opressora das classes dominantes contra os inimigos que as ideologias dessas classes construíram, ou seja, contra os pobres e quem se opunha à forma como a sociedade está organizada. As ideologias que circundam e alicerçam o militarismo, ao mesmo tempo, constroem e combatem o inimigo, transformando parcela da sociedade - sempre a parcela marginalizada - em população incômoda, em inimigos matáveis. Nesse sentido é importante analisar a militarização das polícias como a militarização da política.

A Polícia Militar não está distante da política, pelo contrário, é por ela gerenciada, o que nos faz entender que a militarização de uma é também a militarização da outra. Isso explica o motivo de termos uma polícia que oprime tanto as manifestações populares e que no dia a dia direciona seus fuzis para as favelas. O sistema capitalista necessita da pobreza para existir e utiliza a força policial para agir contra parcela dessa mesma pobreza que ele mesmo não conseguiu administrar, é o que se chama, corretamente, de criminalização da pobreza.

É seguindo a ideologia da classe dominante que PMs de diversos estados ainda prestam homenagens, inclusive em seus fardamentos, ao Golpe Militar de 1964. O processo militar de formação da instituição e dos seus soldados é baseado na existência de um inimigo e não no respeito aos direitos. Ocorre que o Estado não pode continuar a levar essa política para a segurança pública, sob pena de manter povo e polícia como inimigos e, muitas vezes, inimigos mortais. A lógica de tratar o povo, sejam manifestantes, sejam infratores da lei, com o mesmo rigor em que se trata inimigos numa guerra, é um dos motivos do crescimento da criminalidade. O discurso de que a polícia tem que ser mais severa é tão velho quanto falido, não há nada de novo nisso e isso há séculos é implementado. A política de segurança pública, para ser efetiva, deve, necessariamente, respeitar e auxiliar a concretização da dignidade da pessoa, pois quando o Estado retira, mediante violência e humilhações, a dignidade de pessoas está contribuindo para o aumento da criminalidade. 
A incompatibilidade entre militarização das polícias e a implementação de uma pauta emancipadora e libertária de direitos humanos não se restringe às mortes e lesões físicas causadas pelo autoritarismo e violência física estatais. Para Zaffaroni (2014) o papel dos meios de comunicação em massa, que costumam atuar desde cedo na vida das pessoas, é decisivo na introjeção da ordem verticalizante e militarizada. Mesmo que as pessoas vulneráveis ao sistema penal - os pobres e os dissidentes - eventualmente não se amedrontem diante do exercício do poderio penal quando este se apresente com sua máscara de repressão do "inimigo" temem o controle de simples condutas realizadas em público. Abraços, caminhadas na madrugada, vestir-se de modo diferente podem ser condutas veementemente controladas pela totalidade do militarismo (polícia, escola, poder judiciário, meios de comunicação em massa, etc.). Não é unicamente a polícia que é militarizada, as nossas vidas também o são (ZAFFARONI, 2014, pp. 24-25).

As ideias de militarização da vida, seletividade penal e geração de um inimigo matável $^{4}$ ficam ainda mais claras quando passamos a nos debruçar sobre dados que escancaram a relação de conflito entre o Estado e os cidadãos, notadamente negros e negras e pobres, como observa Amparo-Alves (2010), esses dados expressam como que permanecem presentes na nossa sociedade "os argumentos biológicos para a demarcação do corpo negro como fora de controle e fonte de perigo constante" (p.565), mesmo diante das mudanças conceituais verificadas na categoria raça e do seu atual descrédito científico.

No tocante aos dados temos um em especial que desmente, ou pelo menos relativiza, a afirmação de que no Brasil não existe pena de morte. É que o Estudo da Anistia Internacional de 2011 aponta que as polícias do eixo Rio-São Paulo mataram 42\% a mais do que em todos os países onde há pena de morte. Já o Mapa da Violência publicado em 2013 pelo Centro Brasileiro de Estudos Latino-Americanos, mostra que o número de mortes violentas de jovens brancos diminuiu em aproximadamente $20 \%$, entretanto o número de mortes violentas de jovens negros aumentou em torno de $30 \%$. Esse corte racial se agravou ainda mais, como mostra o Mapa da Violência publicado em 2014 pela mesma instituição. Este mapa mais

\footnotetext{
4 "Quem é o ser eminentemente passível de ser punido/executado no contexto da nossa violência fundante? Quem é este ser "matável" e "insacrificável” na economia da violência no Brasil?" (AMPARO-ALVES, 2010, p. 570). A resposta dada pelo autor às suas próprias indagações sugere a utilização do conceito de homo sacer (AGAMBEN, 1995), que se refere àquele cuja condição foge à ótica dos direitos humanos e da cidadania (bios aristotélica), sendo apenas alcançada pela ótica da sua relação crua com o mundo natural (zoé aristotélica).
} 
recente mostra que o número de mortes violentas de jovens brancos diminuiu em aproximadamente $32,3 \%$, entretanto o número de mortes violentas de jovens negros aumentou em torno de $32,4 \%$. A partir de uma leitura que relacione essas estatísticas à nossa tão conhecida realidade social, podemos concluir que há sim pena de morte, mas para os pobres e negros, uma pena de morte extrajudicial, numa situação de aberração institucionalizada que atribui ao militarismo a escolha de quem morre e quem vive.

O que se pretende investigar, com esta pesquisa, são as relações entre militarização das polícias e o campo da política, sobretudo naquilo que se refere às contradições existentes entre, de um lado, os anseios democráticos constituintes do Estado moderno e, de outro, as constantes violações a Direitos Humanos realizadas pelos aparatos militares, em específico as polícias militares brasileiras, bem como demonstrar limitações das linhas tradicionais de direitos humanos para enfrentar essa questão. A vida das pessoas não pode estar a serviço das ideologias das classes dominantes e, portanto, a desmilitarização das polícias, da política e da vida deve manter uma relação dialética com processos de luta que eleve a intervenção de defensores de direitos humanos um patamar emancipador e de lutas, as libertações, emancipações e dignidade deve sem elementos ativos para uma teoria crítica de direitos humanos.

\section{O PROCESSO DIALÉTICO DE CONSTRUÇÃO E ANIQUILAÇÃo Do INDIVÍDUO NÃO PADRONIZADO (OU DO ESTRANHO)}

Bauman (1998) em “O mal-estar na pós-modernidade”, propõe uma reflexão em torno do processo dialético de construção e aniquilação de estranhos dentro de espécies societárias. Partindo das ideias de segurança e ordem como pilares das sociedades modernas, o autor entende os estranhos como indivíduos que não reproduzem os padrões de comportamento previamente formulados por determinados meios sociais. Para Bauman (1998, p. 27) cada sociedade "traça suas fronteiras e desenha seus mapas cognitivos, estéticos e morais [...]", sendo, portanto, responsável por criar seus próprios estranhos.

\footnotetext{
5 Como apontam os principais institutos de pesquisa, a violência letal tem atingido preferencialmente homens jovens negros. AmparoAlves (2010, p. 565) justifica esses dados no modo de construção da masculinidade negra, historicamente fundamentada em estereótipos de impureza, maldade e agressividade. Para o autor, nas narrativas nacionais o homem negro aparece como o "malandro hipersexual, o protótipo do jogador de futebol, ou ainda na figura do exótico e grotesco, sempre de caráter duvidoso" (p. 565). Nessa tarefa de construir os lugares simbólicos do homem negro, para Amparo-Alves (2010) tem contribuído uma antropologia branca que insiste em enfatizar a suposta harmonia nas relações raciais brasileiras, os raros estudos sobre masculinidade no Brasil e a pouca atenção dada ao estudo das formas diferenciadas de acesso aos privilégios do que significa ser homem no país, ou seja, ao questionamento das masculinidades hegemônicas e subalternas. Apesar disso, segundo Amparo-Alves (2010), existem algumas contribuições que discutem as formas racializadas de viver a masculinidade negra, revelam o "script racial" no qual homens negros são estigmatizados como violentos, perversos e maus, e que apontam como que a violência tem sido o princípio organizatório da masculinidade negra. Tudo isso, para o autor, justifica porque "o homem negro é ontologicamente pensando como voraz, constante fonte de perigo, irracional, marginal, cruel" (AMPARO-ALVES, 2010, p.566)
} 
O Estado moderno - responsável por criar seus estranhos - tomava para si a tarefa de aniquilá-los. Por gerar incertezas à ordem não havia espaço, dentro de uma sociedade ordeira e segura, para a diversidade insegura e imprevisível, e a consequência disso era a negação ao diferente. Essa negação tem como elementos a dureza de um Estado arrogante que entendia a coerção como meio mais eficiente para submeter as pessoas a viverem sob suas condições. $\mathrm{O}$ emprego da força era característica da empreitada aniquiladora aos estranhos.

Bauman (1998) não se furtou a utilizar o termo guerra para definir o atrito entre o Estado e as pessoas diferentes, apontado ainda duas estratégias que se alternavam e se complementavam:

[...] Uma era a antropofágica: aniquilar os estranhos devorando-os e depois, metabolicamente, transformando-os num tecido indistinguível do que já havia. Era esta a estratégia da assimilação: tornar a diferença semelhante; abafar as distinções culturais ou linguísticas; proibir todas as tradições e lealdades, exceto as destinadas a alimentar a conformidade com a ordem nova e que tudo abarca; promover e reforçar uma medida, e só uma, para a conformidade. A outra estratégia era antropoêmica: vomitar os estranhos, bani-los dos limites do mundo ordeiro e impedi-los de toda comunicação com o lado de dentro. Era essa a estratégia da exclusão [...] (BAUMAN, 1998, p.28)

Numa percepção de ruptura entre a modernidade e a pós-modernidade o autor enxerga uma diferença não na existência dos estranhos, mas na forma como são criados. Enquanto na modernidade eram estranhos os que não se adaptavam aos padrões previamente estipulados, com rigidez e segurança próprios de uma ordem que almejava produzir um resultado certo e determinado, na pós-modernidade reinam as incertezas:

\footnotetext{
Os estranhos já não são autoritariamente pré-selecionados, definidos e separados, como costumavam ser nos tempos dos coerentes e duráveis programas de constituição da ordem[...] Os estranhos de hoje são subprodutos, mas também os meios de produção no incessante, porque jamais, conclusivo, processo de construção de identidade. (BAUMAN, 1998, p. 37).
}

A relação entre a sociedade pós-moderna e seus estranhos também sofre algumas alterações, notadamente quanto ao aumento da influência do desregrado mercado de consumo - norteado pelo poder econômico. Utilizando o entendimento de Jean-Paul Sartre sobre o "viscoso", Bauman (1998) enxerga como um mal estar na pós-modernidade que as incertezas e os projetos de vida têm como elementos norteadores principais os valores de mercado e, portanto, a viscosidade que geraria o medo aos economicamente privilegiados seria a ausência de poder dos estranhos: 


\begin{abstract}
O tumulto e o clamor chegam, não haja nenhum engano, de outras áreas da cidade, que os consumidores em busca de prazer jamais visitam, deixam viver em paz. Essas áreas são habitadas por pessoas incapazes de escolher com quem elas se encontram e por quanto tempo, ou de pagar para ter suas escolhas respeitadas; pessoas sem poder [...] (BAUMAN 1998, p. 41).
\end{abstract}

Bauman (1998), na tentativa de apontar um "caminho para a humanidade partilhada" propõe uma espécie de consenso sobreposto entre os acúmulos históricos da direita e da esquerda. Se é verdade que na contemporaneidade os dois polos ideológicos mais claros entendem, as diferenças como "produtos humanos" e, portanto, algo bom e desejável, "a teorização sobre a essência humana e os direitos humanos se enganou no sentido de se afastar demais, antes do que de menos, do elemento 'embaraçado' ou 'encaixado' em sua ideia do humano" (BAUMAN, 1998, p. 47).

Em que pese os processos de construção e aniquilação do indivíduo não padronizado não sejam questões epocais, mas sistêmicas, o esforço teórico em torno da busca de um consenso entre polos ideológicos opostos coloca um desafio ético importante: para além dos discursos, tanto de esquerda quanto de direita, a aceitação do diferente deve ser uma prática cotidiana. Entretanto, numa breve análise de posturas de blocos, movimentos, partidos políticos e outras instituições, o que se percebe é que a prática dos que se identificam como direita é mais segregadora e excludente, notadamente no Brasil. Para citar apenas um exemplo, basta levarmos em consideração as recentes posturas parlamentares protagonizadas pela direita tradicional no sentido de impor o Estatuto da Família determinando um núcleo familiar aceitável.

\title{
5 Militarização da SeguranÇa PúbliCa E a InStitucionalizaÇÃo DO EXTERMÍNIO DOS OPRIMIDOS
}

A abordagem da desmilitarização das polícias expõe a necessidade de compreensão dos modos utilizados pelo Estado para promover e executar os seus dispositivos de segurança. Tomando como base a ideia de construção de um inimigo que deve ser exterminado - física, moral e psicologicamente - é interessante a análise das restrições cotidianas que as pessoas sofrem em sua liberdade, restrições em sua maioria das vezes, sequer sentidas. A ideia de segurança pública é, portanto, mais ampla, envolvendo mecanismos de vigilância, disciplina e punição, como bem analisa Foucault (2008): 
Do mesmo modo, o corpus disciplinar também é amplamente ativado e fecundado pelo estabelecimento desses mecanismos de segurança. Porque, afinal de contas, para de fato garantir essa segurança é preciso apelar, por exemplo, e é apenas um exemplo, para toda uma técnica de vigilância, de vigilância dos indivíduos, de diagnóstico do que eles são, de classificação de sua estrutura mental, da sua patologia própria, etc., todo conjunto disciplinar viceja sob os mecanismos de segurança para fazê-lo funcionar. (FOUCAULT, 2008, p.11)

Os mecanismos disciplinares, punitivos e de segurança funcionam concomitantemente. Para Foucault (2008, p.12) “a técnica celular, a detenção em celas é uma técnica disciplinar” e na medida em que a função disciplinar é exercida ela tem como objetivo “consertar” o indivíduo para que ele não cometa mais atos ilegais, portanto é também um mecanismo de segurança.

Tendo como elementos a vigilância, a disciplina e a punição, a segurança deve ser analisada como um conjunto de técnicas e dispositivos que buscam o andamento da sociedade de acordo com determinadas vontades, interesses e direções. Estabelecer determinada conduta como criminosa não ocorre isoladamente, mas tem em conjunto com a ação do Estado no mapeamento da ocorrência dessas condutas, antes e depois, apontando quais os sujeitos que a praticam, aonde a praticam e quais os elementos criminológicos que implicam na ocorrência daquele fato.

Zaffaroni (2014), ao analisar a "deslegitimação do sistema penal e a crise do discurso jurídico-penal", demonstra, com o brilhantismo que lhe é característico, o papel que a militarização exerce nos órgãos do sistema penal. Não obstante, amplia o leque de participantes desse processo de produção militarizado de valores e condutas, trazendo à baila, inclusive, protagonistas estratégicos, no que pertine à produção de valores aceitáveis, como os meios de comunicação, as escolas e outros grupos. É essa construção planejada, dentro de uma perspectiva disciplinadora e extremamente verticalizada, que seleciona os perfis e condutas que devem ser combatidos pelo sistema penal:

Os órgão legislativos, inflacionando as tipificações, não fazem mais do que aumentar o arbítrio seletivo dos órgãos executivos dos sistema penal e seus pretextos para o exercício de um maior poder controlador. A seletividade estrutural do sistema penal - que só pode exercer seu poder regressivo legal em um número insignificante das hipóteses de intervenção planificadas - é a mais elementar demonstração da falsidade da legalidade processual proclamada pelo discurso jurídico-penal. Os órgãos executivos têm 'espaço legal' para exercer poder repressivo sobre qualquer habitante, mas operam quando e contra quem decidem. (ZAFFARONI, 2014, p. 27)

Esse processo de produção de valores e condutas aceitáveis é o próprio responsável pela construção de sua antítese. Ao estabelecer as vestimentas adequadas, os cortes de cabelo 
aceitáveis, as palavras "boas", os vícios lícitos, as religiões nobres, etc., o sistema de organização social estabelece também suas antinomias, portanto, as vestimentas inadequadas, os cortes de cabelo inaceitáveis, as palavras "ruins", os vícios ilícitos, as religiões más, etc.

A mistura da produção de valores inaceitáveis, portanto de inimigos, e de uma segurança pública militarizada não poderia gerar outro resultado senão um desequilíbrio da atuação do poder repressivo estatal, não raro à margem da própria legalidade. Nesse sentido não é exagero afirmar que ter uma polícia militarizada combatendo o inimigo que foi gerado por uma política de Estado opressora, significa institucionalizar o combate, muitas vezes mortal, às minorias.

Os números resultantes dessa mescla podem ser analisados tomando como base o mapa da violência supracitado. O número de negros mortos passou de 29.656 para 41.127 , enquanto o número de brancos assassinados diminuiu de 19.846 para 14.928 .

Entretanto o corte racial não é o único que nos fornece elementos para analisar a seletividade. O gênero também é levado em consideração para mitigação de direitos por parte do sistema penal. Não são raras as notícias de violações a direitos das mulheres por policiais militares. No ano de 2014 foi noticiado um emblemático caso de estupro cometido por policiais da UPP do Jacarezinho no Rio de Janeiro. Rotineiramente PM's de diversos estados desrespeitam a lei e homens revistam mulheres, as notícias de assédio não são raras, notadamente quando as vítimas são prostitutas.

Militarizar a segurança pública implica, portanto, diretamente em exercer opressões, mas não apenas isso. Optar por oprimir através de órgãos militares significa dar aos oprimidos um tratamento de guerra. Isso explica a ostensividade com a qual as Polícias Militares invadem os bairros periféricos em busca de possíveis criminosos. Isso explica a execução sumária de um grande número de seres humanos que por morarem em favelas e terem a pele preta foram rotulados de inimigos matáveis.

Trabalhando com Foucault no seu "A história da sexualidade", Amparo-Alves (2010, p. 571) mostra como o autor iniciou a exploração daquilo que denomina como uma nova arte de governar (FOUCAULT, 1990), o biopoder, que mostra a habilidade do aparato de poder de promover a vida ${ }^{6}$, ainda que por meio da morte, de modo que a "violência é 'sanitarizada', a

\footnotetext{
${ }^{6}$ Amparo-Alves (2010) nos alerta para o fato de que seria apressada a leitura que apontasse nessa visão de Foucault o fim do espetáculo da morte na sociedade contemporânea. Para o autor, "o espetáculo do sofrimento continua sendo uma das maneiras eficientes de os aparatos de poder moderno demonstrarem sua força" (p. 571), ou seja, não estamos na era do pós-espetáculo pois a teatralidade do poder coercitivo do aparato policial brasileiro ainda é marcante na estética militar das polícias, nas demonstrações públicas do seu poderio bélico e nas suas ações letais em público.
} 
partir da justificativa racionalmente calculada o emprego da morte em nome da vida ${ }^{7}$. Não se está indo à guerra para matar, mas para proteger a vida dos 'cidadãos de bem"” (AMPAROALVES, 2010, p. 571).

Como, então, é possível a um poder político matar, incitar a morte, demandar mortes, dar a ordem para matar e expor não apenas seus inimigos, mas também seus próprios cidadãos ao risco de morte? (FOUCAULT, 2003, p. 254).

Amparo-Alves (2010) diz que a resposta a essa indagação de Foucault está na "natureza do racismo como instrumento ideológico que justifica a eliminação e o controle de certas populações. Racismo aparece aqui como uma tecnologia do biopoder.” (p. 571).

Em uma sociedade normativa, raça, ou racismo, é a pré-condição que torna possível a aceitabilidade da matança. [...] é a condição indispensável para o exercício do poder de matar. (FOUCAULT, 2003, p. 256).

Assim, para descrever as relações entre o Estado e suas populações racializadas, Amparo-Alves (2010) utiliza os conceitos de necropoder e necropolítica, sugeridos pelo filósofo nigeriano Aquiles Mbembe ${ }^{8}$ para mostrar como a morte se tornou a base normativa através do qual o Estado exerce o seu direito de matar.

Necropoder [...] diz respeito, portanto, à banalidade da morte nas políticas (supra)estatais de controle e gestão da ordem política, nas noções de direitos humanos e nas concepções que temos de ordem e de paz. (AMPARO- ALVES, 2010, p. 572).

Essa postura de banalização da morte, para Amparo-Alves (2010), permite o entendimento da realidade da juventude negra brasileira a partir da figura do homo sacer de Giorgio Agamben, aquele sob constante ameaça da morte e que por sua condição de nãocidadão pode ser morto sem que seu massacre seja considerado um homicídio (AGAMBEN, 1995, p. 73), pois, "por não merecer viver, sua morte não represente nenhuma incongruência com a defesa da paz e dos direitos humanos." (AMPARO-ALVES, 2010, p. 570).

\footnotetext{
7 Invasões residenciais no meio da noite, as abordagens constantes, as balas perdidas que atingem crianças, os ataques aéreos de helicópteros em comunidades pobres, os autos de resistência, são exemplos dessa "racionalidade que tem a proteção da vida como sua razão de existir" (AMPARO-ALVES, 2010, p. 571).

8 Aquiles Mbembe defende que na descrição dessas relações entre Estado e populações racializadas seria mais apropriado falarmos em políticas da morte (necro-politics), mundos de morte (death-worlds) e estados assassinos (mourderous states).
} 


\section{CONSIDERAÇÕES FINAIS}

Procuramos, no presente trabalho, desenvolver um raciocínio crítico em torno de questões importantes pertinentes à desmilitarização das polícias, buscando identificar elementos que nos permitam uma melhor caracterização do aparato repressor estatal, além de

refletir acerca dos limites das concepções tradicionais do direito que se mostram insuficientes para incidir das estruturas excludentes e opressoras das atuais formas de organização social.

Tendo em vista o que foi abordado, concluímos que a militarização das polícias reflete um padrão de tratamento violento ao cidadão por parte do Estado. A relação entre a bibliografia pesquisada e o estudo estatístico revela que a violência perpetrada pelas polícias não é isolada ou pontual, pelo contrário, é estrutural. Partindo da ideia de inimigo como construção social é possível verificar o papel da polícia num cenário de crise sistêmica. Diante da incapacidade do atual estágio do capitalismo de atender às demandas sociais aumenta a parcela da população sem perspectivas. Uma massa de pessoas pobres não vislumbra mais a possibilidade de ascensão social e o sistema já não tenta reverter esse quadro através de políticas de inclusão. Essa parcela do povo o Estado trata como "população incômoda" e muitas vezes como "inimigos matáveis".

Sob a justificativa de resolver problemas oriundos, tanto de ações criminosas quanto dos anseios modernos de segurança, o Estado passou a reproduzir violência sob o manto da busca pela justiça. Nessa linha de atuação o principal instrumento jurídico para construção social passou a ser o ordenamento penal.

A busca pelo criminoso coloca as polícias militares como protagonistas desse processo. O Estado que tem como base fundamental a proteção à propriedade privada divide o ciclo policial, deixando o papel investigativo para a polícia civil e o ostensivo para as PM’́s. Para justificar a existência desse setor militarizado da segurança pública a eficiência vira sinônimo de altos números de prisões em flagrante, nem sempre justas, e de violações a direitos humanos, jamais justas.

Diante desse cenário o debate em torno da violência de estado e da desmilitarização das polícias revela algumas formas de formulação de padrões de comportamento que são difundidos e tidos como únicos aceitáveis. Os instrumentos de formação de consciência e ideologia cumprem um papel importante ao difundir referidos padrões. Essa construção é 
extremamente verticalizada e violenta, invadindo várias esferas da vida privada e todos os momentos da formação da personalidade.

$\mathrm{Na}$ busca por uma sociedade segura, em que os valores e condutas tragam as consequências previstas, a humanidade passou a temer aquilo que não está dentro da ideia de ordem. A construção do indivíduo rompe com suas aptidões e anseios mais íntimos para atender as exigências do atual estágio de organização social. Os comportamentos buscados são sempre os característicos do homem, hetero, branco, jovem, europeu e bem sucedido economicamente.

Discutir a desmilitarização das polícias atualmente é enfrentar os processos de padronização de condutas e de extermínio das diversidades, apontando a necessidade de desconstrução dessa cultura verticalizada e violenta que, ao invadir vários momentos e fases da formação dos indivíduos, termina por militarizar as nossas vidas.

\section{REFERÊNCIAS}

AGAMBEN, Giorgio. State of exception. Chicago: University of Chicago Press, 2005. 1995.

.Homo sacer: sovereign power and bare life. Stanford,CA: Stanford University Press,

BAUMAN, Zygmunt. O mal-estar da pós-modernidade. Rio de Janeiro: Zahar, 1998. COMPARATO, Fábio Konder. A afirmação histórica dos direitos humanos. 6. ed. rev. E atual. São Paulo: Saraiva, 2008.

FOUCAULT, Michel. History of sexuality: an introduction. New York:Vintage Books, 1990.

. Segurança, Território, População. São Paulo: Martins Fontes, 2008.

Society must be defended: lectures at the Collegede France, 1975-76. New York: Picador, 2003.

GOHN, Maria da Glória. História dos movimentos e lutas sociais: a construção da cidadania dos brasileiros. 5. ed. São Paulo: Edições Loyola, 2001.

HERRERA FLORES, Teoria crítica dos direitos humanos - os direitos humanos como produtos culturais. Rio de Janeiro: Editora Lumen Juris, 2009.

A reinvenção dos direitos humanos. Florianópolis: Fundação Boiteux, 2009. 
LIMA, Igor Frederico Fontes de. Militarização das polícias: a face antidemocrática do estado de direito. In: SILVA, Givanildo Manoel da (Org.). Desmilitarização da polícia e da política: uma resposta que virá das ruas. Uberlândia: Pueblo, 2015. p. 170-173.

MACHADO, Marta Rodriguez de Assis. Sociedade do risco e do direito penal: uma avaliação de novas tendências político-criminais. São Paulo: IBCCRIM, 2005.

MARCONI, Marina de Andrade; LAKATOS, Eva Maria. Fundamentos de metodologia científica. 5. ed. São Paulo: Atlas, 2003.

MBEMBE, Achilles. Necropolitics. Public Culture, Duke, v. 15, n.1, p. 11-40, 2003.

MARX, Karl. Crítica da filosofia do direito de Hegel. 3. ed. São Paulo: Boitempo, 2013. MELOSSI, Dario; PAVARINI, Massimo. Cárcere e fábrica - As origens do sistema penitenciário (século XVI-XIX). 2. ed. Rio de Janeiro: Editora Revan, 2006.

NAGENGAST, Carole. Violence, terror and the crisis of state. Annual Review of Anthrpology, v. 23, p. 109-136, 1994.

PACHUKANIS, E. B. Teoria Geral do Direito e Marxismo. 1. ed. São Paulo: Editora Acadêmica, 1988.

PASTANA, Débora Regina. Justiça penal no Brasil contemporâneo. Discurso Democrático, prática autoritária. São Paulo: UNESP, 2009.

PIOVESAN, Flávia. Direitos humanos e justiça internacional: um estudo comparativo dos sistemas regionais europeu, interamericano e africano. 2. ed. São Paulo: Saraiva, 2011.

RUIZ, Jefferson Lee de Souza. Direitos humanos e concepções contemporâneas. 1. ed. São Paulo: Cortez, 2014

RUSCHE, Georg; KIRCHHEIMER, Otto. Punição e estrutura social. 2. ed. Rio de Janeiro: Editora Revan, 2004.

SANCHEZ RUBIO, David. Encantos e desencantos dos direitos humanos: de emancipações, libertações e dominações. 1. ed. Porto Alegre: Livraria do Advogado, 2014.

MAD, 2007.

. Repensar derechos humanos. De la anestesia a la sinestesia. Sevilla: Editorial

SANTOS, Boaventura de Sousa. Renovar a teoria crítica e reinventar a emancipação social. São Paulo: Boitempo, 2007.

WACQUANT, Loic. Punir os pobres: a nova gestão da miséria nos EUA [A onda punitiva]. 3. ed. Rio de Janeiro: Editora Revan, 2003

WOLKMER, Antonio Carlos. Introdução ao Pensamento Jurídico Crítico. 3. ed. São Paulo: Saraiva, 2001. 
ZACCONE, Orlando. Indignos de vida: a forma jurídica de extermínio de inimigos na cidade do Rio de Janeiro. Rio de Janeiro: Editora Revan, 2015.

Revan, 2007.

Acionistas do nada - Quem são os traficantes de drogas. Rio de Janeiro: Editora

ZAFFARONI, Eugenio Raúl. Em busca das penas perdidas: a perda da legitimidade do sistema penal. 5. ed. Rio de Janeiro: Editora Revan, 2014. 